\title{
Metástase no músculo reto inferior como sinal de apresentação de adenocarcinoma renal: relato de caso
}

\author{
Inferior rectus muscle metastasis as a presenting sign of renal cell carcinoma: \\ case report
}

\author{
Allan Christian Pieroni Gonçalves \\ Patrícia Grativol Costa ${ }^{2}$ \\ Mario Luiz Ribeiro Monteiro ${ }^{3}$
}

\begin{tabular}{|l|}
\hline RESUMO \\
\hline Proptose e diplopia decorrentes de alargamento de músculo extra-ocular \\
representam importante sinal de apresentação de várias afecções da \\
órbita. Embora a causa mais comum de alargamento de músculo extra- \\
ocular seja a orbitopatia distiroidiana, o diagnóstico diferencial destas \\
doenças é extenso. Relatamos neste trabalho o caso de um paciente com \\
história de diplopia e proptose unilateral de três meses que apresentava \\
importante espessamento isolado do músculo reto inferior direito e após \\
investigação clínica, radiológica e biopsia incisional teve o diagnóstico \\
de tumor metastático de células renais para o músculo reto inferior. Há \\
poucos casos relatados de metástases para a musculatura ocular extrín- \\
seca sendo assim nosso objetivo relatar um novo caso, revisar a literatura \\
e reforçar a inclusão deste distúrbio no diagnóstico diferencial do \\
espessamento da musculatura extra-ocular.
\end{tabular}

Descritores: Carcinoma de células renais; Metástase neoplásica; Exoftalmia; Músculos oculomotores; Neoplasias orbitárias; Diplopia; Relatos de casos [tipo de publicação]

\section{INTRODUÇ̃̃̃O}

Proptose e diplopia decorrentes do alargamento de músculo extra-ocular representam sinais importantes em várias afecções da órbita. Embora a causa mais comum de alargamento de músculo extra-ocular seja a orbitopatia distireoidiana onde o diagnóstico é estabelecido pelo quadro clínico característico associado aos achados radiológicos e laboratoriais, nas formas atípicas a diferenciação com outras causas de alargamentos dos músculos retos se torna menos evidente. O diagnóstico diferencial destas doenças é extenso e inclui: miosite inflamatória idiopática, granulomatose de Wegener, sarcoidose, triquinose e outras parasitoses, fístula carótidocavernosa, metástases, tumores linfóides além de tumores primários ${ }^{(1-13)}$. Nestas afecções o acometimento dos músculos é difuso envolvendo mais de um músculo extra-ocular e não raro em ambas as órbitas. $\mathrm{O}$ aumento de volume de um único músculo extra-ocular pode sugerir a existência de um tumor primário de órbita como descrito no rabdomiossarcoma, lipossarcoma, tumor de granulócitos e sarcoma alveolar de tecidos moles ${ }^{(9,12)}$ embora $^{-}$ também possa ocorrer nos tumores metastáticos ou até mesmo na orbitopatia distireoidiana e no pseudotumor orbitário.

O objetivo deste trabalho é relatar um caso de proptose progressiva secundária a metástase para músculo reto inferior isolado como primeiro sinal de um adenocarcinoma de células renais, revisar a literatura e reforçar a inclusão desta doença no diagnóstico diferencial do espessamento da musculatura extra-ocular. 


\section{RELATO DE CASO}

Paciente de 58 anos notou proptose progressiva no olho direito e diplopia vertical há 3 meses. Como antecedente pessoal relevante referia tabagismo por 30 anos. Ao exame oftalmológico apresentava acuidade visual com melhor correção de 20/30 no olho direito (OD) e 20/20 no olho esquerdo (OE). Apresentava defeito pupilar aferente relativo e proptose com aumento da resistência a retropulsão à direita, com exoftalmometria de Hertel de 32 mm (OD) e 20 mm (OE). A avaliação da motilidade ocular evidenciou uma exotropia e hipertropia do olho direito com restrição a infradução do OD (Figura 1). Não foram observadas alterações na biomicroscopia. O exame fundoscópico revelou papila elevada, com limites borrados, associada a dobras de coróide e tortuosidade venosa no olho direito e olho esquerdo sem alterações.

A tomografia computadorizada e a ressonância magnética de crânio e órbitas evidenciaram lesão expansiva orbitária na topografia do músculo reto inferior. O músculo reto inferior do OD apresentava-se com expressivo aumento no diâmetro de forma nodular com bordos nítidos (Figuras 2 e 3 ).

Submetido a avaliação sistêmica, verificou-se massa no pólo inferior do rim esquerdo sugestivo de tumor de células renais e múltiplos nódulos pulmonares sugestivo de metástases. Foi realizada a biópsia do músculo reto inferior através de uma orbitotomia transconjuntival e o estudo anátomo-patológico da peça confirmou a hipótese clínica de adenocarcinoma metastático compatível com sítio primário renal (Figura 4). O paciente foi submetido a nefrectomia radical do rim esquerdo e imunoterapia. $\mathrm{Na}$ órbita foi realizada radioterapia local devido ao grande crescimento do tumor metastático porém não houve regressão. A proptose progrediu nos meses seguintes resultando em úlcera de córnea e infecção secundária do globo

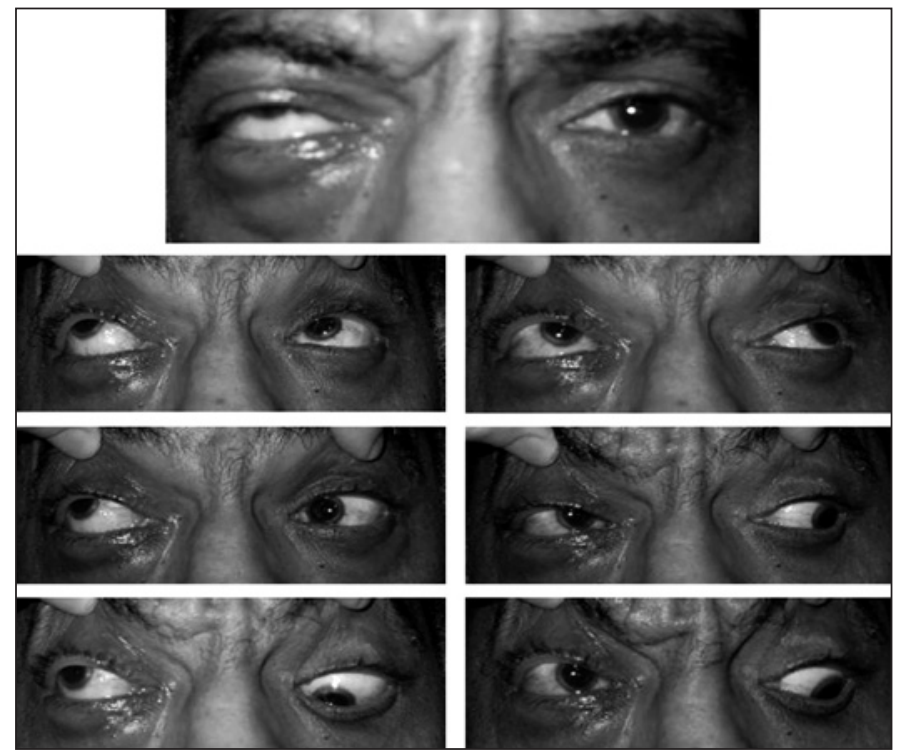

Figura 1 - Exame das versões, mostrando exotropia e hipertropia do olho direito ocular. Frente a este quadro foi realizada uma nova abordagem cirúrgica orbitária de exenteração parcial com enxerto de pele.

Decorrido 1 ano após o diagnóstico o paciente está sendo acompanhado em nosso serviço em processo de adaptação de prótese orbitopalpebral (Figura 5).

\section{DISCUSS ÃO}

A órbita é um sítio pouco comum das metástases cancerosas. Mais de $90 \%$ dos casos de metástases ocorrem em pacientes com idade acima dos $40 \operatorname{anos}^{(3)}$. Metástases na órbita são menos comuns que metástases para o globo ocular. Dentre todos tumores orbitários, as metástases representam menos de $10 \%{ }^{(5-6)}$. A maioria das metástases orbitárias são carcinomas sendo os sarcomas e melanomas considerados pouco comuns. Dentre os tumores metastáticos da úvea a maioria também são derivados de carcinomas primários ${ }^{(3)}$. O carcinoma de mama, de próstata e pulmonar são os sítios primários da grande maioria das metástases orbitárias. De acordo com varias séries sobre metástases orbitárias na literatura o sítio primário renal representa apenas $3 \%$ dos $\operatorname{casos}^{(3-4)}$.

Geralmente a localização da metástase orbitária ocorre na loja

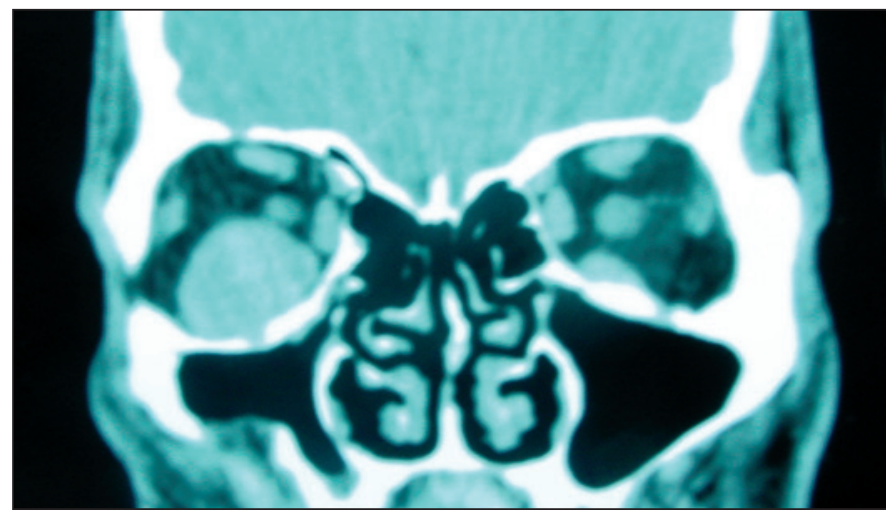

Figura 2 - Tomografia computadorizada das órbitas mostrando alargamento do músculo reto inferior direito

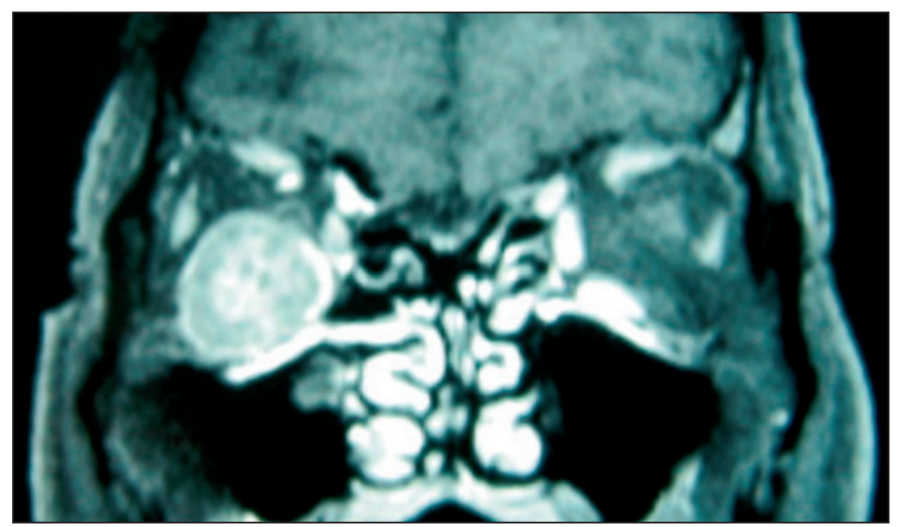

Figura 3 - Ressonância magnética das órbitas mostrando alargamento do músculo reto inferior direito 
anterior, entre esclera posterior e pálpebras ${ }^{(3)}$. O envolvimento da musculatura ocular extrínseca ocorre na maioria das vezes pela contigüidade de massas orbitárias ${ }^{(5,7)}$. Metástase em órbita que se apresenta com envolvimento apenas da musculatura extrínseca isoladamente sem alterações associadas de outras estruturas orbitárias é um evento bastante incomum. Menos de $5 \%$ estão localizadas nos músculos oculares extrínsecos ${ }^{(8)}$.

O quadro clínico da metástase orbitária não é específico.

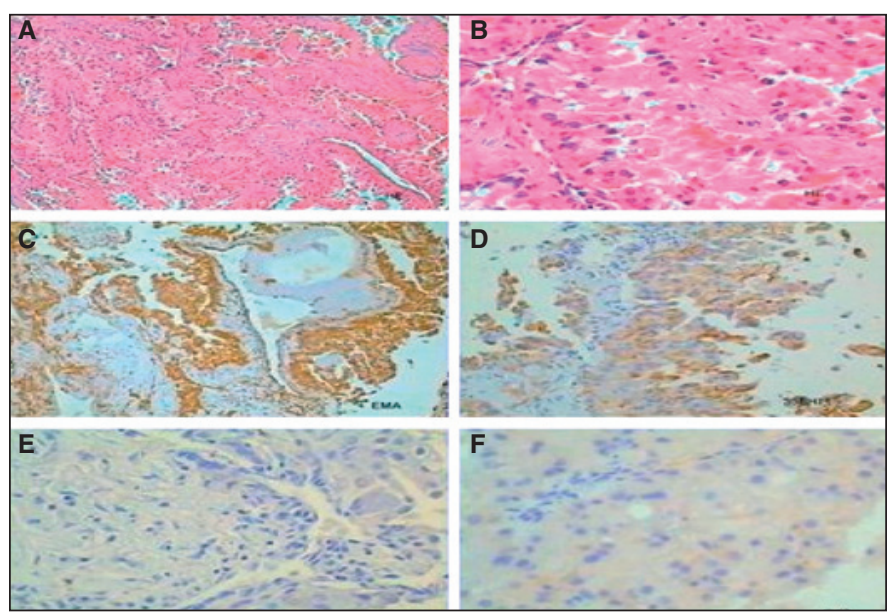

Figura 4 - Lâminas A e B: Histologia da lesão (HE 40x e 400x) compatível com adenocarcinoma. As seguintes lâminas apresentam estudo imunohistoquímico onde foram pesquisados os seguintes antígenos pela técnica da imunoperoxidase; Lâmina C: EMA (positivo); Lâmina D: 35 BH 11 (positivo); Lâmina E: CEA (negativo) e Lâmina F: Citoqueratina 7 (negativo). Resultados compatíveis com sítio primário renal.
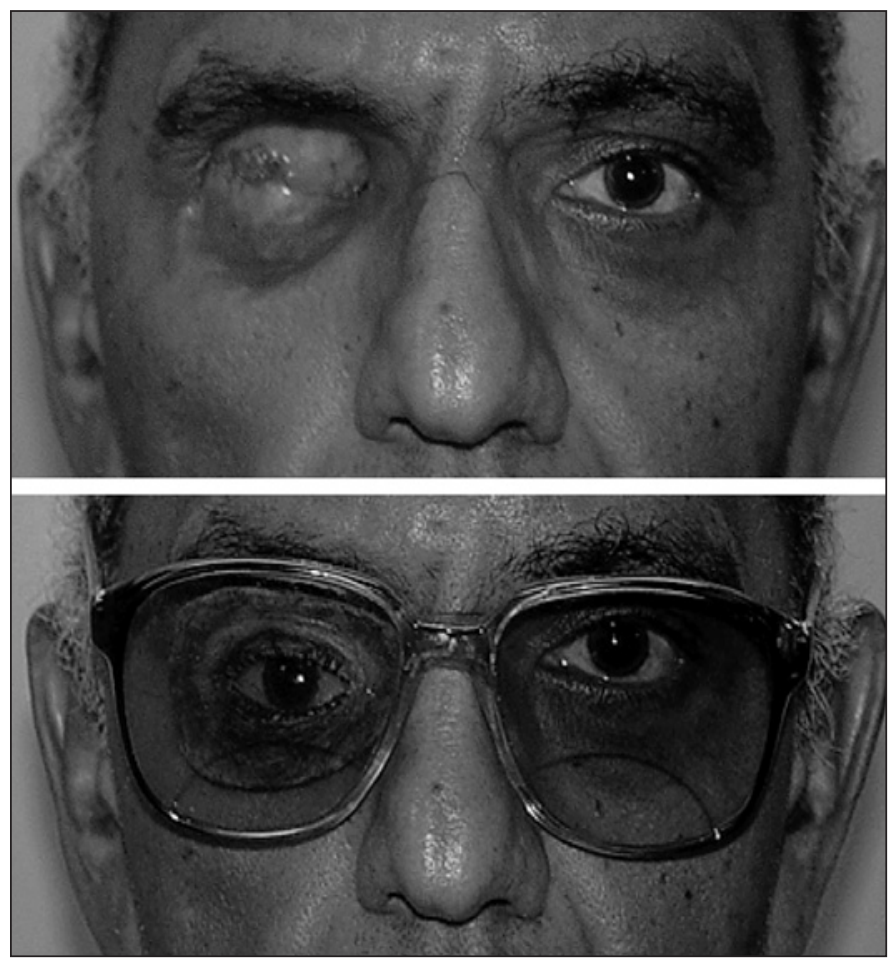

Figura 5 - Pós-operatório tardio da exenteração de órbita direita
Apresenta-se geralmente como qualquer outra lesão expansiva orbitária com proptose, hiperemia conjuntival, diplopia ou uma própria massa palpável. Porém a história de rápida progressão, em meses, do quadro além da unilateralidade relatada em nosso caso também foi observada em outros relatos sobre metástases orbitárias ${ }^{(1,3-5,9)}$. As metástases orbitárias são unilaterais em mais de $90 \%$ dos casos, diferentemente das metástases de úvea onde $25 \%$ das afecções são bilaterais ${ }^{(3)}$.

No início, o correto diagnóstico de metástase orbitária é dificultoso. Sinais e sintomas inespecíficos podem mascarar a metástase como outra doença da órbita. E em ocasiões onde este envolvimento orbitário precede qualquer história ou sintomatologia do sítio neoplásico primário este diagnóstico torna-se ainda mais complexo. Ademais, metástases orbitárias podem ocorrer tardiamente ao sítio primário, assim devemos considerar também histórias remotas de processo neoplásico $^{(14)}$. Metástases orbitárias de carcinoma renal podem ocorrer até 20 anos depois da ressecção cirúrgica do tumor primário ${ }^{(4)}$.

Entre 70 pacientes com história detalhada na série de Shields $81 \%$ dos pacientes apresentavam história positiva do sítio neoplásico primário e $19 \%$ apresentavam a orbitopatia como primeiro sinal da doença ${ }^{(3)}$. No caso do carcinoma de células renais, quando há metástase orbitária, esta geralmente é a primeira manifestação clínica do câncer. Apresenta-se em $75 \%$ dos casos como o primeiro sinal da doença ${ }^{(4,9)}$.

Quadros orbitários sugestivos de metástase devem ser sempre submetidos a uma história detalhada associada a uma avaliação sistêmica do paciente conjuntamente com o clínico geral, ginecologista, urologista, pediatra ou outros especialistas dependendo da suspeita diagnóstica ${ }^{(2)}$. Aproximadamente $50 \%$ das pesquisas sistêmicas são positivas para detecção do sítio primário da neoplasia ${ }^{(3)}$.

Nos exames de imagem a tomografia representa a principal, e quase sempre fundamental, ferramenta de estudo. A ressonância magnética é um instrumento também muito útil e em alguns casos necessária na obtenção de maiores detalhes de partes moles ${ }^{(3,5)}$.

Os estudos de imagem demonstram alguns padrões sugestivos de tumores metastáticos, porém, também não específicos. O exame de tomografia computadorizada pode revelar massas infiltrativas ou circunscritas a estruturas orbitárias, como a glândula lacrimal, as paredes ósseas ou a musculatura extrínseca ${ }^{(15)}$. Quando acometem isoladamente a musculatura extrínseca os tumores entram no diagnostico diferencial do espessamento muscular não tireóideo ${ }^{(10)}$. Os tumores metastáticos semelhantemente a tumores primários da órbita são na maioria unilaterais e envolvem apenas um músculo reto isoladamente. Ocorre um predomínio de afecção dos músculos retos horizontais. Apresentam-se geralmente como um espessamento nodular de bordos nítidos e sem o envolvimento dos tendões. Destruição óssea, formação de molde ósseo, alargamento orbitário ou evidências de extensão neoplásica a estruturas vizinhas são muito incomuns dos tumores metastáticos da órbita. O espessamento muscular difuso com borramento de suas bordas pode ocorrer, simulando miosite. O padrão de 
imagem radiológica não apresenta tanta especificidade a ponto de evitar outros procedimentos diagnósticos definitivos ${ }^{(5,10)}$.

A especificação do tipo histológico do tumor é importante e é realizada através do exame anátomo-patológico do tecido tumoral orbitário colhido por biopsia. A biopsia pode ser efetuada através de punção por agulha fina ou orbitotomia aberta. Em muitos casos a localização do tumor é suficientemente anterior para a realização de uma abordagem não tão agressiva como a transconjuntival ou transpalpebral. Em localizações mais posteriores a punção por agulha fina pode ser uma boa opção embora exija patologista e cirurgião experientes. Porém a grande utilidade da punção por agulha fina ocorre em casos onde se tem história prévia de tumor primário e há apenas a necessidade da confirmação de que a lesão tumoral é mesmo metastática, no intuito de direcionar o tratamento ${ }^{(2-3)}$. No nosso caso, apesar da identificação da lesão neoplásica primária no rim, foi decidido que a biopsia orbitária seria o procedimento menos invasivo e mais confiável para identificação do tipo histológico do tumor.

O tratamento preconizado do carcinoma de células renais é a nefrectomia, pois aumenta a sobrevida ${ }^{(11)}$. A remoção do carcinoma renal primário pode levar a regressão do secundário $^{(14)}$. Quando há uma lesão orbitária solitária deve-se tratar a órbita também, mesmo com a possibilidade de micrometástases estarem presentes em outros locais ${ }^{(1)}$. Este tratamento pode ser realizado com a exérese cirúrgica, se possível, ou com a radioterapia. Como o carcinoma de células renais é radiosensível, a radioterapia é o principal recurso terapêutico no tratamento orbitário. Em nosso caso foi realizado primeiramente o tratamento da lesão orbitária com radioterapia. Esta abordagem não apresentou resultado, com progressivo crescimento da massa tumoral. Foi necessária a realização da exenteração orbitária decorrente da complicação infecciosa e estética que a exoftalmia não responsiva a radioterapia promoveu.

O carcinoma de células renais tem caráter agressivo. Aproximadamente $25 \%$ de todos os pacientes quando fazem diagnóstico já tem metástases à distância e a sobrevida gira em torno de 33-45\% em 5 anos e 18-22\% em $10 \operatorname{anos}^{(4)}$.

As metástases de adenocarcinoma renal devem ser consideradas como diagnóstico diferencial dos tumores metastáticos orbitários assim como dos espessamentos não tireoidianos da musculatura ocular extrínseca. Assim como em nosso relato, metástase orbitária como sinal de apresentação apesar de incomum já foi documentado por outros autores ${ }^{(1,3-5,14)}$.

Embora o diagnóstico de uma lesão metastática configure por si só um prognóstico reservado, a evolução do conhecimento nas terapêuticas oncológicas tem possibilitado cada vez mais o aumento da sobrevida dos pacientes com câncer.

A avaliação sistêmica deve ser prontamente realizada para determinar a extensão da doença metastática com o fim de instituir assim que possível o tratamento necessário. Apesar de pouco comum as metástases orbitárias devem ter uma especial atenção dos oftalmologistas uma vez que o diagnóstico precoce de tais doenças tem grande influência sobre o prognóstico e a mortalidade do paciente.

\section{ABSTRACT}

Proptosis and diplopia due to enlargement of extraocular muscles represent important presenting signs of many orbital disorders. Although dysthyroid ophthalmopathy is the most common cause of enlargement of extraocular muscles, the differential diagnosis is extensive. We report a patient with a 3-month history of diplopia and unilateral proptosis and a markedly enlarged inferior rectus muscle on imaging studies. A biopsy of the lesion followed by systemic evaluation established the diagnosis of metastatic renal cell carcinoma. There are few cases of metastatic tumors to the extraocular muscles reported in the literature and thus our objective is to report a new case, review the literature and reiterate the inclusion of this disorder in the differential diagnosis of enlargement of the extraocular muscles.

Keywords: Carcinoma, renal; Neoplasm Metastasis; Oculomotor muscles; Orbital neoplasms; Diplopia; Exophthalmos; Case reports [publication type]

\section{REFERÊNCIAS}

1. Holt BA, Holmes SA, Kirby RS. Renal cell carcinoma presenting with orbital metastases. Br J Urol. 1994;75(2):246-7.

2. Monteiro MLR. Tumores orbitais. In: Dantas AM, Monteiro MLR. Doenças da órbita. Rio de Janeiro: Cultura Médica, 2002. p.201-48.

3. Shields JA, Shields CL, Brotman HK, Carvalho C, Perez N, Eagle RC Jr. Cancer metastatic to the orbit: the 2000 Robert M. Curts Lecture. Ophthal Plast Reconstr Surg. 2001;17(5):346-54.

4. Parnes RE, Goldberg SH, Sassani JW. Renal cell carcinoma metastatic to the orbit: a clinicopathologic report. Ann Ophthalmol. 1993;25(3):100-2.

5. Capone A Jr, Slamovits TL. Discrete metastasis of solid tumors to extraocular muscles. Arch Ophthalmol. 1990;108(2):237-43.

6. Bloch RS, Gartner S. The incidence of ocular metastatic carcinoma. Arch Ophthalmol. 1971;85(6):673-5.

7. Shields JA, Bakewell B, Augsburger JJ, Flanagan JC. Classification and incidence of space-occupying lesions of the orbit. A survey of 645 biopsies. Arch Ophthalmol. 1984;102(11):1606-11.

8. Velten IM, Gusek-Schneider GC, Tomandl B. [Diplopia as first symptom of a bronchogenic carcinoma] Klin Monatsbl Augenheilkd. 2000;217(1):52-4. German.

9. Slamovits TL, Burde RM. Bumpy muscles. Surv Ophthalmol. 1988;33(3): 189-99.

10. Patrinely JR, Osborn AG, Anderson RL, Whiting AS. Computed tomographic features of nonthyroid extraocular muscle enlargement. Ophthalmology. 1989; 96(7):1038-47. Comment in: Ophthalmology. 1990;97(1):4-5.

11. Bennett JC, Plum F. Cecil Textbook of Medicine. 20th ed. Philadelphia (PA): Saunders; 1996.

12. Monteiro ML. Liposarcoma of the orbit presenting as an enlarged medial rectus muscle on CT scan. Br J Ophthalmol. 2002;86(12):1450.

13. Rothfus WE, Curtin HD. Extraocular muscle enlargement: a CT review. Radiology. 1984;151(3):677-81.

14. Kindermann WR, Shields JA, Eiferman RA, Stephens RF, Hirsch SE. Metastatic renal cell carcinoma to the eye and adnexae: a report of three cases and review of the literature. Ophthalmology. 1981;88(12):1347-50.

15. Rootman J, Ragaz J, Cline R, Lapointe JS. Orbital metastasis. In: Rootman J, editor. Diseases of the orbit. Philadelphia: J.B. Lippincott; 1988. p.405-27. 